\title{
Erratum to: Proceedings of the American Society for Enhanced Recovery/Evidence Based Peri-Operative Medicine 2016 Annual Congress of Enhanced Recovery and Perioperative Medicine
}

\section{Washington, D.C., USA, 20-22 April 2016}

Charles R. Horres", Mohamed A. Adam, Zhifei Sun, Julie K. Thacker, Timothy E. Miller and Stuart A. Grant

\section{Erratum}

Following publication of the original article (Horres et al. 2016) it was brought to our attention that one of the author names for A1 (Effects of enhanced recovery pathways on renal function) was inaccurately represented due to a typo. Please therefore note that the author name Timothy J. Miller should instead read as Timothy E. Miller. We apologise for any inconvenience caused.

Received: 21 September 2016 Accepted: 21 September 2016

Published online: 07 October 2016

\section{Reference}

Horres CR, Adam MA, Sun Z, Thacker JK, Miller TE, Grant SA. Proceedings of the

American Society for Enhanced Recovery/Evidence Based Peri-Operative

Medicine 2016 Annual Congress of Enhanced Recovery and Perioperative

Medicine. Perioper Med. 2016;5 Suppl 1:A1.

\footnotetext{
*Correspondence: crhorres32@gmail.com

Duke University School of Medicine, Durham, NC, USA
} 